\title{
Food Intake and Overweight in School-Aged Children in Germany: Results of the GINIplus and LISAplus Studies
}

\author{
Zhengcun Pei ${ }^{\mathrm{a}, \mathrm{b}} \quad$ Claudia Flexeder $^{\mathrm{a}} \quad$ Elaine Fuertes $^{\mathrm{a}, \mathrm{g}}$ Marie Standl ${ }^{\mathrm{a}}$ \\ Anette Buyken $^{c}$ Dietrich Berdel ${ }^{d}$ Andrea von Berg ${ }^{\mathrm{e}}$ Irina Lehmann ${ }^{\mathrm{e}}$ \\ Beate Schaaf $^{f}$ Joachim Heinrich ${ }^{\text {a }}$ for the GINIplus and LISAplus Study Group \\ a Institute of Epidemiology I, Helmholtz Zentrum München - German Research Center for Environmental Health, \\ Neuherberg, ${ }^{b}$ Faculty of Medicine, Ludwig Maximilian University of Munich, Munich, ' University of Bonn, \\ IEL-Nutritional Epidemiology, DONALD Study at the Research Institute of Child Nutrition, Bonn, dDepartment of \\ Pediatrics, Marien Hospital Wesel, Wesel, e Department of Environmental Immunology, UFZ-Centre for Environmental \\ Research, Leipzig, and ${ }^{\mathrm{f}}$ Medical Practice for Pediatrics, Bad Honnef, Germany; ${ }^{9}$ School of Population and Public Health, \\ University of British Columbia, Vancouver, B.C., Canada
}

\section{Key Words}

Food intake · Overweight · Child · BMI z-score · Energy partition model $\cdot$ Epidemiology

\section{Abstract \\ Objective: To investigate the cross-sectional association be- tween food intake and overweight in children. Methods: Height and weight were measured in 2,565 school-aged chil- dren. Intakes of 11 food groups were categorized (low, me- dium and high) using specific tertile cutoffs. Multivariate en- ergy partition models were applied. Adjustment included energy intake from other food groups, city, family income, parental education and 'screen' time. Possible underreport- ers were identified and used in sensitivity analyses. Results: Compared to low intake, high intakes of meat, fish, bever- ages and bakery products were associated with greater BMI $z$-scores $[\beta(95 \% \mathrm{Cl})=0.32(0.21,0.42), 0.13(0.03,0.24), 0.23$ $(0.11,0.35)$ and $0.10(-0.01,0.20)]$ and increased risk of being overweight [odds ratio $(\mathrm{OR})(95 \% \mathrm{Cl})=2.08(1.58,2.73), 1.39$}

$(1.08,1.80), 1.36(1.01,1.84)$ and $1.62(1.24,2.11)]$. Conversely, medium and high intakes of confectionery were associated with smaller BMI z-scores $[\beta=-0.18(-0.28,-0.07)$ and $-0.22(-0.33,-0.12)]$ and decreased risk of being overweight [OR $=0.64(0.50,0.83)$ and $0.53(0.40,0.68)]$. These associations were robust to sensitivity analyses. Conclusions: Intakes of meat, fish, beverages and bakery products correlate with body weight status.

(c) 2014 S. Karger AG, Basel

\section{Introduction}

Obesity is a major public health concern $[1,2]$. Childhood obesity often persists into adulthood and can substantially decrease quality of life [3], increase the risk of metabolic syndrome and adult morbidities $[4,5]$, and be a heavy financial burden on the public health system [6].

Obesity is mainly a consequence of an unbalanced energy status [7]. Hence, the influence of diet (intake of in-

\begin{tabular}{ll}
\hline KARGER & $\begin{array}{l}\text { @ 2014 S. Karger AG, Basel } \\
0250-6807 / 14 / 0641-0060 \$ 39.50 / 0 \quad \text { Openger }\end{array}$ \\
$\begin{array}{l}\text { E-Mail karger@karger.com } \\
\text { www.karger.com/anm }\end{array}$ & $\begin{array}{l}\text { This is an Open Access article licensed under the terms of the } \\
\text { Creative Commons Attribution-NonCommercial 3.0 Un- } \\
\text { ported license (CC BY-NC) (www.karger.com/OA-license) } \\
\text { applicable to the online version of the article only. Distribu- } \\
\text { tion permitted for non-commercial purposes only. }\end{array}$
\end{tabular}

Dr. Joachim Heinrich

Institute of Epidemiology I, Helmholtz Zentrum München German Research Center for Environmental Health

Ingolstädter Landstr. 1, DE-85764 Neuherberg (Germany)

E-Mail heinrich@helmholtz-muenchen.de 
dividual nutrients and certain food items, dietary patterns and habits) and energy intake have been considered in many studies on the etiology of obesity [8-11]. However, the findings are difficult to reconcile $[12,13]$. Several different types of models (i.e. standard multivariate model, residual nutrient model, energy partition model, multivariate nutrient density model) are commonly used in epidemiological studies, which are adjusted for total energy intake (TEI) [14]. The results of these models can and have been interpreted using different perspectives. One important difference between energy partition models and other types of models mentioned above is that the coefficient calculated from this former type of model represents both energy and nonenergy associations with the nutrient. The coefficient obtained from other model types leads to isocaloric substitution interpretations [14, 15]. Isocaloric interpretations are problematic when TEI is associated with the outcome under study [14], which may be one potential explanation for the conflicting results of previous studies. Another possibility could be the misreporting of energy intake in dietary assessment [16]. Moreover, selective reporting possibly exists. Results from the ALSPAC study revealed that underreporters had lower records of fat-/sugar-containing foods such as biscuits, cakes, chocolates and sweets [17]. Additionally, factors including food habits and portion size estimation, as well as ethnicity and cultural differences, may also influence the accuracy of food intake data [16].

The association between food intake with BMI zscores and being overweight during childhood remains controversial [18]. In the current study, we used data from two German birth cohorts to examine cross-sectionally whether the intake levels of specific food groups are associated with being overweight or obese at the age of 10 years, after adjusting for energy from all other food groups and other potential confounding factors.

\section{Materials and Methods}

\section{Study Population}

Data from two ongoing German birth cohort studies were used in the current analysis. GINIplus (German Infant Nutritional Intervention Plus Environmental and Genetic Influences on Allergy Development) is an ongoing birth cohort study initiated to prospectively investigate the influence of a nutritional intervention during infancy, as well as air pollution and genetics on allergy development. GINIplus participants ( $\mathrm{n}=5,991$ newborns) were recruited from obstetric clinics in Munich and Wesel between September 1995 and July 1998. Details of the study design are described elsewhere [19]. During the first 4 months, a total of 2,252 newborns with atopic heredity participated in a hydrolyzed pro- tein infant formula intervention study [20]. This randomized controlled study showed that the BMIs of children at 1 year were marginally different among the formula groups, but not at 6 and 10 years of age [21].

LISAplus (Influences of Lifestyle-Related Factors on the Immune System and the Development of Allergies in Childhood Plus Air Pollution and Genetics) is an ongoing birth cohort examining the impact of lifestyle-related factors, air pollution and genetics on immune system and allergy development in childhood. In total, 3,097 neonates were recruited from 14 obstetrical clinics in $\mathrm{Mu}$ nich, Leipzig, Wesel and Bad Honnef between November 1997 and January 1999. A detailed description of the study's screening and recruitment has been described previously [22].

During the 10-year follow-up, information on food intake was collected from 3,437 participants (2,194 from GINIplus, 1,243 from LISAplus) by means of a validated semiquantitative food frequency questionnaire (FFQ). Height and weight were measured for 3,116 participants (1,918 from GINIplus, 1,198 from LISAplus) during the 10-year physical examinations. In the current study, 2,565 children (1,308 males, 1,257 females) from GINIplus ( $\mathrm{n}=$ $1,596)$ and LISAplus ( $\mathrm{n}=969)$ with complete data on FFQ and BMI are included (fig. 1).

Approval by the respective local ethics committees (Bavarian General Medical Council, University of Leipzig, Medical Council of North Rhine-Westphalia) and written consent from all participating families were obtained for both studies.

\section{Definition of Outcomes: BMI z-Scores and Overweight}

Weight and height were measured by physicians during the 10year physical examinations. BMI values were calculated and transformed to age- and sex-specific BMI z-scores using WHO macros [23]. Children were defined as being overweight or obese using the BMI $\mathrm{z}$-score standard deviation (SD), according to WHO guidelines [24]. Children with BMI z-scores greater than one SD (BMI $\mathrm{z}$-score $>+1 \mathrm{SD})$ were defined as overweight. Children of normal weight (BMI $z$-score $\leq+1 \mathrm{SD}$ ) were used as the reference group in all models. As the number of obese (BMI z-score $>+2$ SD) children was small $(n=116)$, we included these children with the overweight group.

\section{Definition of Predictors: Eleven Food Groups}

The details and effectiveness of the FFQ have been published elsewhere [25]. Briefly, information on food intake frequencies and portion sizes of 82 food items were collected using parentcompleted questionnaires. Seventy-nine food items were grouped into 11 food groups according to the Codex General Standard for Food Additives' food category system [26]. We excluded three food items: nut nougat cream, water and syrup. Nut nougat cream has a complex composition and could not be adequately classified into one food group. Syrup intake was very low in the current study. Water intake was excluded as its consumption does not yield energy. However, we used water intake as an additional adjustment variable when assessing the association between beverage intake and the outcomes, as beverage intake is reported to be associated with water intake [27]. Information on the intake of sweeteners, salts, spices, soups, sauces and foodstuffs intended for particular nutritional uses were not available in the current study.

For each of the 11 food groups, the intake for each child in grams per day was calculated. Because the distributions of the food 
Fig. 1. Flow chart of the study population.

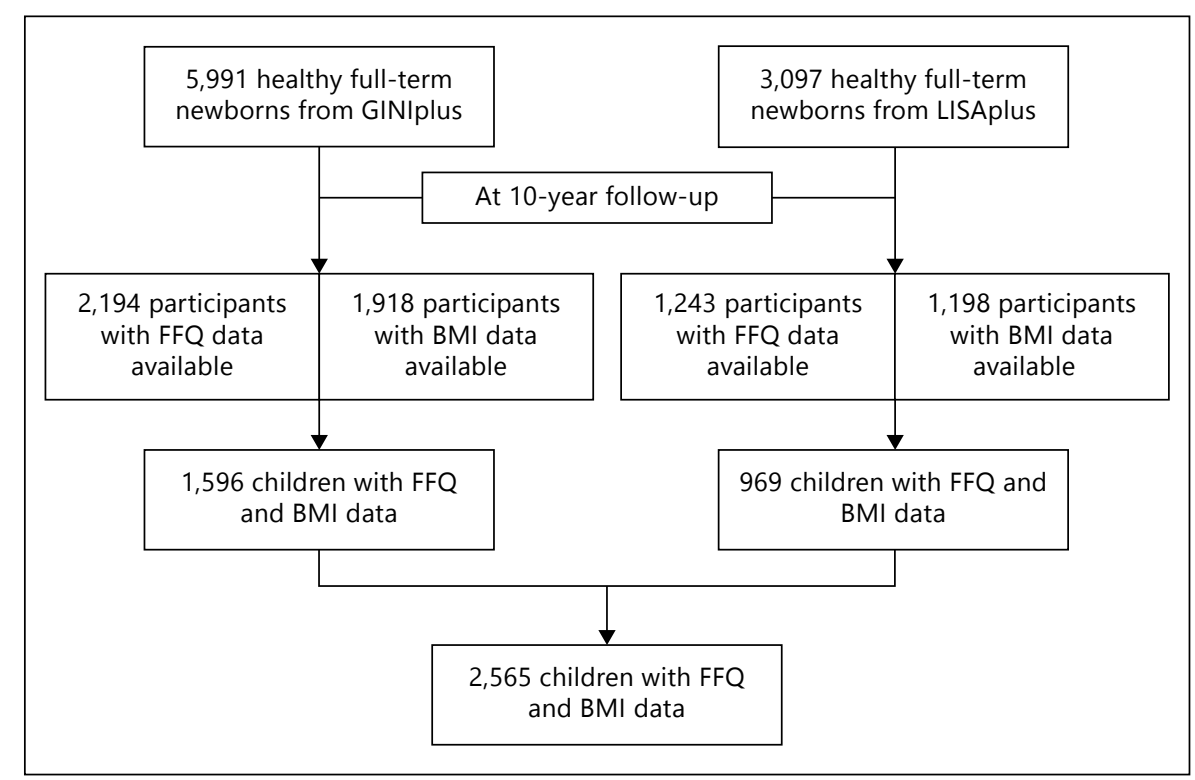

intakes were positively skewed, we categorized these values into three levels (low, medium, high) using group- and sex-specific tertile cutoffs.

\section{Potential Confounding Factors}

We included several potential confounding factors that confound the association between food intake and the outcomes of interest. The set of covariates examined were city of residence (Munich, Wesel, Bad Honnef, Leipzig), parental education level, family income and 'screen time'. Parental education levels were defined according to the highest number of years either parent attended school (low $<10$, medium $=10$ and high $>10$ ). Family income was defined into three categories according to the city-specific quartiles of monthly average income (low $<25 \%$, medium $25-75 \%$ and high $>75 \%$ ). We used time spent in front of a screen (including TV, video and computer viewing), referred to as 'screen time', as a sedentary behavior covariate, as sedentary behavior has been associated with greater increases in BMI between the ages of 9 and 15 years [28]. This variable was collapsed into two categories: low screen time included children who spent $<1 \mathrm{~h}$ per day in summer and $<2 \mathrm{~h}$ per day in winter in front of a screen, and high screen time included children who spent $\geq 1 \mathrm{~h}$ per day in summer and $\geq 2 \mathrm{~h}$ per day in winter in front of a screen. In addition, there were 15 children who spent $<1 \mathrm{~h}$ per day in summer and $\geq 2 \mathrm{~h}$ per day in winter in front of a screen. These children were placed in the high screen time category.

We additionally defined a variable 'underreporter versus plausible energy intake reporter' based on a ratio of TEI to basal metabolic rate (BMR). BMR is estimated using height, weight and age according to Mifflin et al. [29]. Because approximately $70 \%$ of total energy expenditure is used for basal life processes [30], we defined an underreporter as a child with $0.7 \times \mathrm{TEI}<\mathrm{BMR}$. A plausible energy intake reporter was defined as a child with $0.7 \times \mathrm{TEI} \geq \mathrm{BMR}$. As the estimation of BMR and the cutoff used to differentiate underreporters and plausible energy intake reporters may not be entirely accurate [31], this variable was not included in the final models, but rather was used for descriptive and sensitivity analyses only.

\section{Statistical Analysis}

As preliminary analyses suggested no differences in the associations between food intakes and BMI z-scores by sex, data for males and females were pooled for all analyses. For each of the 11 food groups, unadjusted and multivariate energy partition models [15] were used to examine the associations between each food group intake (in grams per day) with BMI z-scores and being overweight. Low intake levels were used as the reference group in all models. According to the definition of the partition model [14], we calculated energy intake from the food group itself and energy intake from all other food groups. Instead of TEI, energy intake from all other food groups was included as a covariate in the models. For each food group, there was a specific energy intake from all other food groups.

Differences between respondents and nonrespondents as well as overweight and normal weight subjects were tested using Pearson's $\chi^{2}$ test for categorical variables and Student's $t$ test for continuous variables. Study characteristics are described using means and $\mathrm{SD}$ or $\mathrm{n}(\%)$. Model results are presented as linear regression coefficients $(\beta)$ for BMI z-scores and odds ratios (OR) for being overweight, with corresponding 95\% CI [ $\beta$ (95\% CI) or OR $(95 \%$ $\mathrm{CI})$, respectively]. All analyses were performed using the statistical software package $\mathrm{R}$, version 2.14.1 [32].

Additional sensitivity analyses were performed. To examine whether the formula intervention in the GINIplus study attenuated our results, sensitivity analyses in which the models were additionally adjusted for formula type were conducted. To study the potentially existing underreporting issue in the present study, analyses were stratified by 'underreporter versus plausible energy intake reporter'. In addition, sensitivity analyses adjusting for this variable in the pooled models were performed. To compare the effect size of the associations between food items that had similar dietary content with BMI z-scores and being overweight, we performed analyses in several pairs: red meat (i.e. pork, beef, sausage) versus white meat (i.e. chicken), freshwater fish versus saltwater fish, fish sticks versus other fish subgroups, vegetables versus fruits 
Table 1. Characteristics of study population at 10 years of age with available BMI and FFQ data $(\mathrm{n}=2,565)$

\begin{tabular}{lc}
\hline & Mean $(\mathrm{SD})$ or $\%(\mathrm{n} / \mathrm{n})$ \\
\hline Female & $49.0(1,257 / 2,565)$ \\
Study & \\
$\quad$ GINIplus & $62.2(1,596 / 2,565)$ \\
$\quad$ LISAplus & $37.8(969 / 2,565)$ \\
City of residence & \\
$\quad$ Munich & $56.1(1,438 / 2,565)$ \\
$\quad$ Leipzig & $9.3(238 / 2,565)$ \\
$\quad$ Bad Honnef & $4.9(125 / 2,565)$ \\
$\quad$ Wesel & $29.8(764 / 2,565)$ \\
Family income & \\
$\quad$ Low & $21.3(499 / 2,346)$ \\
Medium & $48.0(1,126 / 2,346)$ \\
$\quad$ High & $30.7(721 / 2,346)$ \\
Parental education & \\
$\quad$ Low & $4.7(120 / 2,555)$ \\
$\quad$ Medium & $26.0(665 / 2,555)$ \\
High & $69.3(1,770 / 2,555)$ \\
High screen time & $31.4(796 / 2,532)$ \\
Age at 10-year physical examination, & \\
months & $122.5(2.7)$ \\
BMI, kg/m ${ }^{2}$ & $17.3(2.4)$ \\
BMI z-score & $0.16(1.05)$ \\
BMI z-score category & \\
Normal weight & $80.3(2,059 / 2,565)$ \\
Overweight & $19.7(506 / 2,565)$ \\
TEI, kcal & $2,082(606)$ \\
\hline &
\end{tabular}

a Defined according to quartiles of monthly average income: low $<25 \%$, medium $25-75 \%$ and high $>75 \%$. ${ }^{\mathrm{b}}$ Categorized according to the highest number of years either parent attended school: low $<10$ years, medium $=10$ years and high $>10$ years. ${ }^{\mathrm{c}}$ Low for $<1 \mathrm{~h}$ per day in summer and $<2 \mathrm{~h}$ per day in winter; high for $\geq 1 \mathrm{~h}$ per day in summer and $\geq 2 \mathrm{~h}$ per day in winter. ${ }^{\mathrm{d}}$ Calculated using WHO macros [23]. ${ }^{\mathrm{e}}$ According to WHO guidelines [24].

and chocolate/chocolate bars versus soft sweets. We additionally investigated associations between BMI z-scores and the individual food items which had been combined into the bakery products and beverages food groups.

\section{Results}

Characteristics of the study population at 10 years of age are shown in table 1 . Female participants comprised $49.0 \%$ of the sample. The mean BMI z-score was 0.16 , which suggests that the majority of the study population had a larger BMI than the reference population. The SD was approximately 1.00 , as expected [33]. The prevalence of overweight was $19.7 \%$. The average TEI was $2,082 \pm$
$606 \mathrm{kcal}$. The characteristics of children included in the current analyses and those from the original birth cohorts who were not included are significantly different in the following three aspects: weight of children at age 10 years, family income at age 10 years and parental education level. The children who were excluded from the present study were more likely to be overweight at age 10 years (25.4\%), from low-income families (25.2\%) and to have parents with low education level (13.0\%) compared to those included in this analysis $(19.7,21.3$ and $4.7 \%$, respectively; data not shown).

The proportion of underreporters among overweight and normal weight participants is shown in table 2. Compared to participants of normal weight, there was a significantly higher proportion of underreporters among overweight participants for both males and females (32.6 vs. $19.2 \%$ and 27.6 vs. $17.1 \%$, respectively; $\mathrm{p}<0.001$ ). Details of which food items were grouped into which food groups are shown in table 3 . The food intake of each food group in grams per day as well as percent energy consumed per day is shown in table 4 .

The adjusted coefficients for the association between food group intakes and BMI z-scores at 10 years of age are shown in figure 2. Compared to children with a low intake of meat and meat products, children with medium and high intakes had greater BMI z-scores $[\beta=0.10(0.00$, $0.20)$ and $0.32(0.21,0.42)$, respectively]. Children with high fish and beverage intakes had greater BMI z-scores than those with low fish and beverage intakes $[\beta=0.13$ $(0.03,0.24)$ and $0.23(0.11,0.35)$, respectively]. Compared to children with a low intake of confectionery, children with medium and high confectionery intakes had smaller BMI $z$-scores $[\beta=-0.18(-0.28,-0.07)$ and $-0.22(-0.33$, -0.12 ), respectively]. No significant associations were found for the rest food groups.

Adjusted ORs for the association between food intake groups and being overweight at 10 years of age are shown in figure 3. Compared to low-intake groups, those with high intakes of meat, bakery products, fish and beverages had a higher risk of being overweight $[\mathrm{OR}=2.08(1.58$, 2.73), $1.62(1.24,2.11), 1.39(1.08,1.80)$ and $1.36(1.01$, $1.84)$, respectively]. Furthermore, those with medium and high intakes of confectionery were at a decreased risk of being overweight $[\mathrm{OR}=0.64(0.50,0.83)$ and $0.53(0.40$, $0.68)$, respectively]. No significant associations were found for the other food groups. Additional adjustment for formula type did not substantially change our results (data not shown).

Adjusting additionally for 'underreporter versus plausible energy intake reporter' attenuated the effect 
Table 2. Underreporters ${ }^{\mathrm{a}}$ by weight status in the study population, stratified by sex

\begin{tabular}{|c|c|c|c|c|c|c|}
\hline \multirow[t]{2}{*}{ Weight status ${ }^{\mathrm{b}}$} & \multicolumn{2}{|l|}{ Male } & \multicolumn{2}{|l|}{ Female } & \multicolumn{2}{|l|}{ Total } \\
\hline & underreporter & $\begin{array}{l}\text { plausible energy } \\
\text { intake reporter }\end{array}$ & underreporter & $\begin{array}{l}\text { plausible energy } \\
\text { intake reporter }\end{array}$ & underreporter & $\begin{array}{l}\text { plausible energy } \\
\text { intake reporter }\end{array}$ \\
\hline Normal weight, n (\%) & $200(19.2)$ & $841(80.8)$ & $174(17.1)$ & $844(82.9)$ & $374(18.2)$ & $1,685(81.8)$ \\
\hline Overweight $^{\mathrm{c}}, \mathrm{n}(\%)$ & $87(32.6)$ & $180(67.4)$ & $66(27.6)$ & $173(72.4)$ & $153(30.2)$ & $353(69.8)$ \\
\hline
\end{tabular}

${ }^{a}$ Underreporter: BMR <70\% TEI; plausible energy intake reporter: BMR $\geq 70 \%$ TEI. ${ }^{b}$ Normal weight: BMI z-score < +1 SD; overweight: BMI z-score $\geq+1 \mathrm{SD}$. ${ }^{\mathrm{c}}$ Significant difference between overweight and nonoverweight groups, tested by Pearson's $\chi^{2}$ test, $\mathrm{p}<0.001$.

Table 3. Definition of food groups ${ }^{\mathrm{a}}$

\begin{tabular}{ll}
\hline Food groups & Food items included \\
\hline Dairy and dairy products & cheeses, milk and yogurts, cream, fresh cream \\
\hline Fats and oils & butter and margarines, oils \\
\hline Fruits and vegetables & $\begin{array}{l}\text { cooked potatoes, nuts, pumpkin, pine seeds, sunflower seeds, carrots, peppers, spinach, chard, cabbage, } \\
\text { lettuce, apples, pears, citrus fruits, berries }\end{array}$ \\
\hline Confectionery & chocolate, chocolate bars, soft sweets \\
\hline Cereal & muesli, cereals, corn flakes, crispy, rice, pasta, noodles \\
\hline Bakery products & $\begin{array}{l}\text { bread, toast, multigrain bread, whole-wheat bread, white rolls, pretzels, croissants, chocolate rolls, cakes, } \\
\text { pastries, cookies, biscuits }\end{array}$ \\
\hline Meat and meat products & pork, beef, veal, poultry, organ meats, sausage, salami \\
\hline Fish and fish products & freshwater fish, saltwater fish, herring, fish sticks, canned fish \\
\hline Eggs and egg products & egg, scrambled egg, fried egg, semolina, pudding, rice pudding \\
\hline Beverages & $\begin{array}{l}\text { fruit juices, fruit nectars, vegetable juices, diluted juices, sparkling drinks, lemonade, cola, ice tea, sport drinks, } \\
\text { energy drinks, tea }\end{array}$ \\
\hline Ready-to-eat savories & crisps, chips, croquettes, pizza \\
\hline \multicolumn{1}{l}{ a Defined according to the Codex General Standard for Food Additives food category system [26]. } \\
\hline
\end{tabular}

Table 4. Distribution of food intake in the study population (g/day)

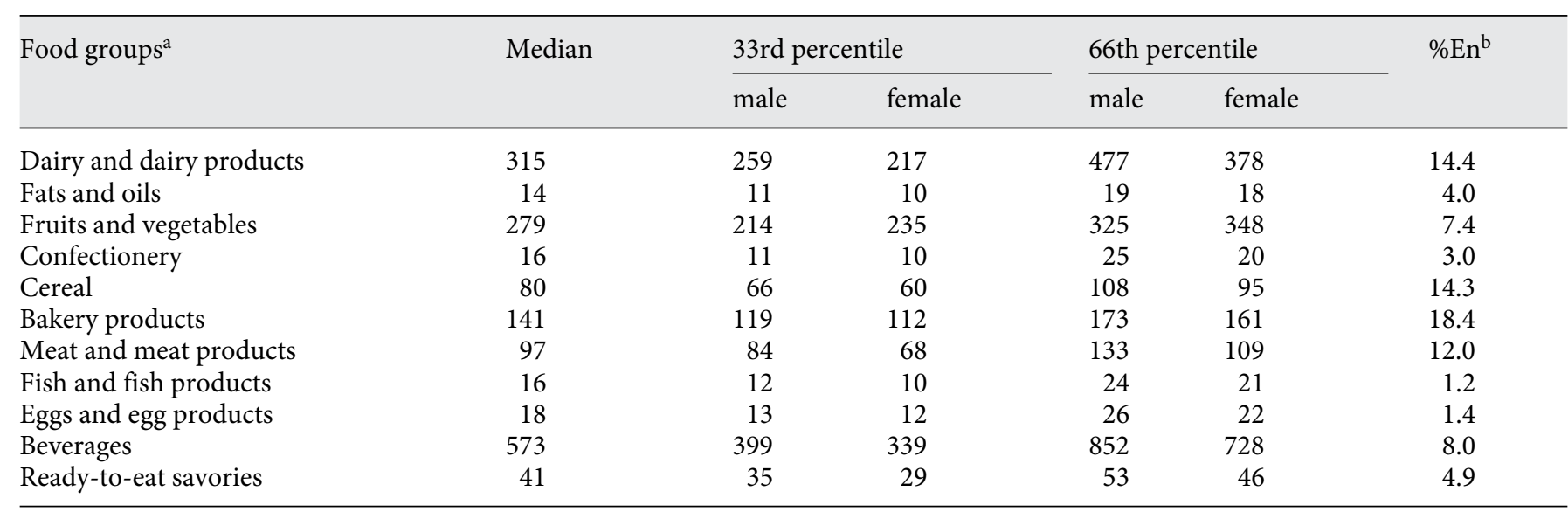

\footnotetext{
${ }^{a}$ Defined according to the Codex General Standard for Food Additives food category system [26]. ${ }^{\text {}}$ Median percent energy consumed per day.
} 
Fig. 2. Adjusted coefficients for the association between food group intake tertiles and BMI z-scores. Models are adjusted for energy intake from other food groups, city of residence, family income, parental education and screen time. ${ }^{\mathrm{a}}$ The association between beverage intake and BMI z-scores was additionally adjusted for water intake.

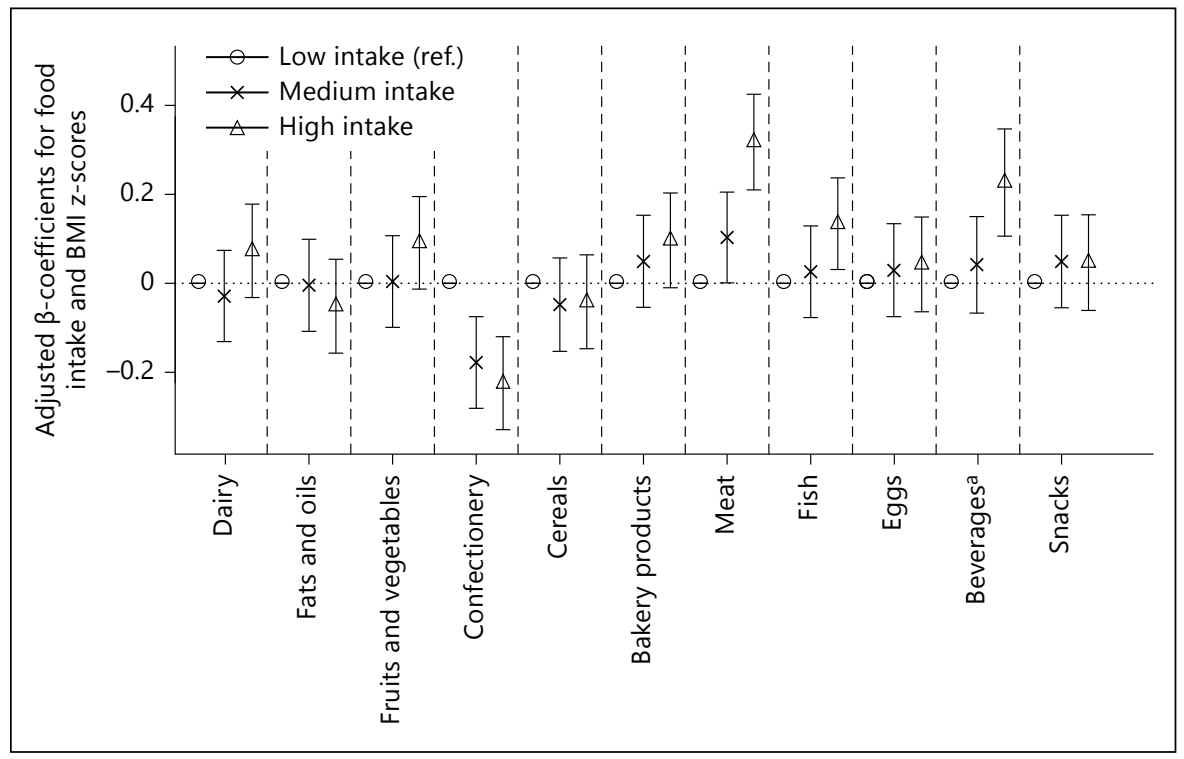

Fig. 3. Adjusted OR for the association between food group intake tertiles and being overweight. Models are adjusted for energy intake from other food groups, city of residence, family income, parental education and screen time. ${ }^{\text {a }}$ The association between beverage intake and being overweight was additionally adjusted for water intake.

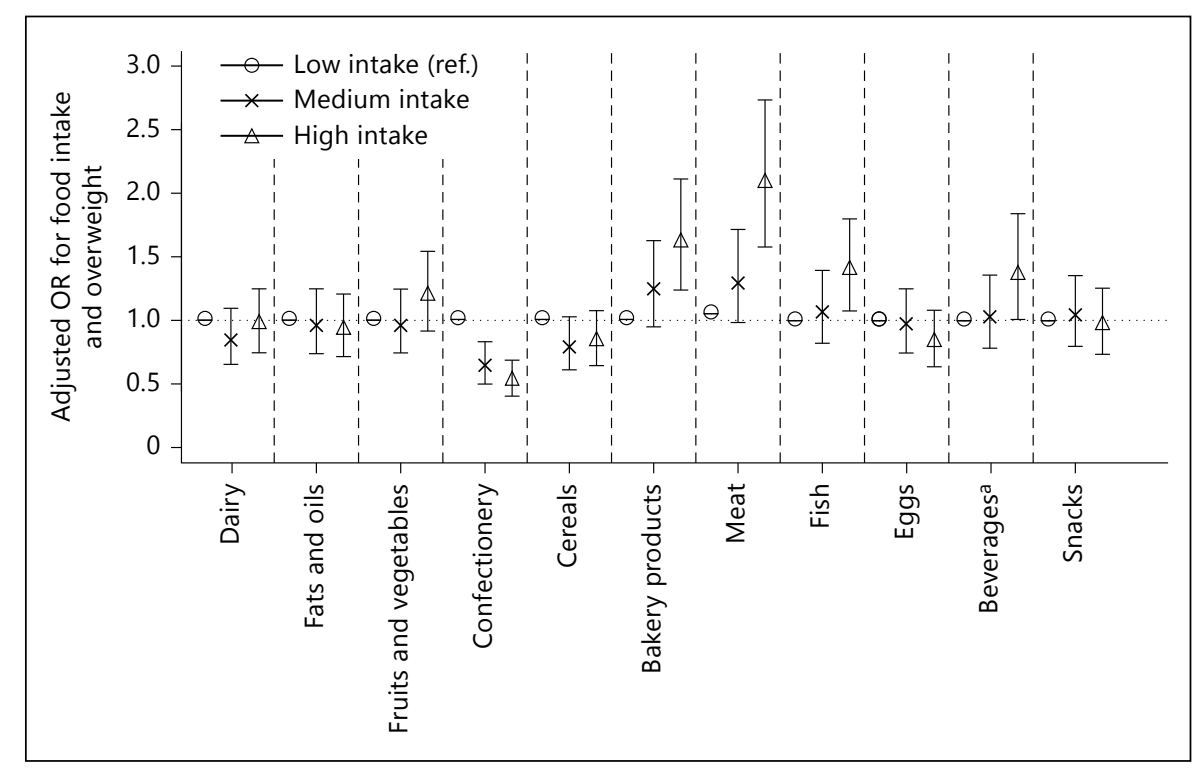

size, but the association between BMI z-scores and confectionery intake was still significant $[\beta:-0.18(-0.28$, $-0.07)$ vs. $-0.12(-0.23,-0.02)$ and $-0.22(-0.33,-0.12)$ vs. $-0.13(-0.24,-0.03)$ for medium and high intake of confectionery before and after adjustment, respectively]. The association between being overweight and confectionery intake also remained significant with attenuated effect size [OR: $0.64(0.50,0.83)$ vs. $0.71(0.55,0.93)$ and $0.53(0.40,0.68)$ vs. $0.63(0.48,0.82)$ for medium and high intake of confectionery before and after adjustment, respectively]. Moreover, effect estimates for un- derreporters were not notably different than those for plausible energy intake reporters. Detailed numbers are provided in online supplementary table 1 (www.karger. com/doi/10.1159/000362694).

Analyses stratified by red meat and white meat yielded significantly positive associations with BMI $z$-scores $[\beta$ for medium intake: $0.07(-0.03,0.18)$ vs. $0.27(0.11,0.42)$ and $\beta$ for high intake: $0.20(0.09,0.31)$ vs. $0.22(0.13,0.31)$ for red meat and white meat, respectively] and being overweight [OR for medium intake: $1.16(0.89,1.52)$ vs. 1.77 $(1.22,2.58)$ and OR for high intake: $1.57(1.20,2.06)$ vs. 
$1.64(1.31,2.05)$ for intake of red meat and white meat, respectively] for both subgroups. Also, the analyses stratified by freshwater fish and saltwater fish showed similar results [OR for medium intake: $1.22(1.01,1.65)$ vs. 1.27 $(1.00,1.66)$ and OR for high intake: $1.28(1.02,1.68)$ vs. $1.32(1.02,1.72)$ for freshwater fish and saltwater fish, respectively]. High intake of fish subgroups that exclude fish sticks was significantly associated with being overweight [OR: $1.47(1.15,1.87)]$, but this was not the case for high fish stick intake $[0.94(0.75,1.19)]$. Analyses stratified by fruit and vegetables yielded a marginally significant association between high intake of vegetable and increased BMI $z$-score $[\beta: 0.11(0.01,0.22)]$. However, high vegetable intake was not associated with being overweight [OR: $1.26(0.97,1.64)]$. Analyses stratified by chocolate/chocolate bars and soft sweets revealed that chocolate/chocolate bars had smaller estimate coefficients than soft sweets [medium intake: $0.67(0.52,0.87)$ vs. $0.94(0.73,1.22)$ and high intake: $0.68(0.53,0.89)$ vs. $0.71(0.55,0.92)$, respectively]. The estimate coefficients only slightly differed among the different bakery food items, and were all significant (data not shown). The effect estimates and significance in sugar-sweetened beverages (e.g. cola, nectars, lemonade, energy drinks, etc.) were greater compared to that in juices (e.g. fruit juices, diluted juices, vegetable juices, etc.); the associations between BMI z-scores and beverages were all significant (data not shown).

\section{Discussion}

In the present study, we observed significant positive cross-sectional associations between high intakes of meat, fish, bakery products and beverages with BMI z-scores and with being overweight at 10 years of age. Moreover, confectionery intake was negatively associated with BMI $\mathrm{z}$-scores and being overweight. Additional model adjustments for energy reporting status and other sensitivity analyses did not substantially change our results.

\section{Meat and Fish Intake and BMI}

Although data from the cross-sectional KiGGS study $(\mathrm{n}=13,450)$ revealed a similar association between high intake of meat with overweight and obesity in 3- to 17 -year-old children [34], our findings should be interpreted with caution as our study is cross-sectional. Animal protein may play a role in the associations, as meat and fish are rich in it. Results from the DONALD study showed significantly positive associations between animal protein intake during puberty and fat-free mass in young adulthood [35], which is in line with evidence from randomized controlled trials in children $[36,37]$ and adults [38]. Thus, the association between BMI and intake of meat and fish may be a reflection of accumulating fat-free mass. The association between BMI z-scores and fat mass and fat-free mass is reported to vary according to the degree of body fatness (overall multiple $\mathrm{R}^{2}$ ranged from 0.90 to 0.96) [39]. Among children with BMI zscores $>+1$, BMI z-scores were more strongly associated with fat-free mass than fat mass. In contrast, among children with $\mathrm{BMI} \mathrm{z}$-scores $\leq+1$, BMI z-scores were more strongly associated with fat mass than fat-free mass [39].

Several studies have reported positive associations between protein intake during early life $(<1$ year) and obesity in childhood [40-42]. The hypothesis behind this observation is that higher protein intake during early life is associated with faster weight gain [40]. However, the protein intake of rapid growers at 2 years of age did not influence the change in BMI z-scores between 2 and 5 years of age in the DONALD study [43]. Our study population (of 10 -year-old children) is nearing puberty, a developmental stage during which fast weight gain is possible. Whether protein intake in puberty contributes to weight gain remains unclear, could not be addressed in this analysis and needs to be explored in future studies.

Meat consumption has been identified as a lifestyle indicator in several adult studies $[44,45]$. Compared to vegetarians, meat consumers had lower education levels, lower socioeconomic statuses and lower household incomes. These factors may have an impact on the onset of obesity [46,47]. Overall, the associations between meat intake with BMI z-scores and being overweight were robust, regardless of which models were used or which confounders were considered. These consistent associations highlight the need for future prevention and intervention against overweight and obesity among children.

\section{Confectionery Intake and BMI}

We observed negative associations between confectionery intake and BMI z-scores. Associations between confectionery intake and BMI z-scores are conflicting $[48,49]$. We believe there are two possible explanations for our results. First, the seemingly protective effect of confectionery might be attributable to reverse causation. An energy-dense, high-fat, low-fiber dietary pattern has been identified as a correlate of increased adiposity during childhood and adolescent [50]. Parents of overweight or obese children, or the children themselves, may have consciously reduced or limited their confectionery intake to lose weight. This artifact would have caused the results
Pei et al. 
to indicate that children of normal weight consume more chocolate and candies than overweight children. Moreover, potential reporting bias may be possible as underreporters usually have higher weight statuses $[16,50,51]$. It is also possible that children and parents underreported the intake of 'unhealthy food' [17]. However, adjusting for underreporters did attenuate the effect size, but the association was still significant. Second, as sugars can stimulate satiety in the short term ( $2 \mathrm{~h})$ [52], intake of confectionery could have reduced subsequent food intake, which could lead to lower BMI. In the current study, the overall energy contribution of confectionery was low (median percent energy consumed per day: $3.0 \%$ ), which does not support a major causal role of confectionery for high BMI.

O'Neil et al. [53] examined the effect of candy consumption on obesity using data from the NHANES study in 11,181 participants (age ranged from 2 to 18 years). Candy consumers (approx. 25\% of the total population) had lower ORs for being overweight $(0.78,95 \%$ CI: $0.68-$ $0.90)$ and obese (0.74, 95\% CI: $0.66-0.82)$ after adjusting for sex, ethnicity, age and energy intake. Another study in 1,139 Saudi Arabian males aged 10-14 years reported that children who consumed sweets and candy one or more times per day were at a higher risk of being overweight (OR: 1.7, 95\% CI: 1.3-2.3). However, this OR was not adjusted for potential covariates [54].

\section{Intakes of Bakery Products and Beverages and BMI}

In the current study, 11 kinds of bread or cakes were combined into a bakery products group (e.g. whole-grain bread, refined bread, cream cake, etc.). The materials used in the production of these items likely differ (e.g. polyols, sugar alcohols, natural sweeteners, sucrose, etc.). Therefore, the associations between BMI z-scores and these food items were examined individually. However, the estimate coefficients of different bakery food items only slightly differed. In general, bakery products belong to medium-to-high glycemic index categories [55], which may help explain the associations between BMI and consumption of bakery products [56]. In addition, reverse causation and misreporting may exist in the association between bakery product intake and overweight, as bakery products are also energy-dense, high-fat, low-fiber food $[17,50]$. Therefore, the true OR may be even larger than observed. However, to which extent these possibilities may affect the results must be interpreted cautiously. For example, with confectionery and bakery products, intake of confectionery is usually between meals, which is likely to be restricted (especially for overweight children); how- ever, bakery products are always consumed during meals, and a child is unlikely to skip main meals even if he is overweight. Thus, the potential effect of reverse causation may be stronger for confectionery intake compared to bakery products. Future studies are needed to explore these possibilities in different food groups.

Previous studies suggest a possible link between intake of soft drinks with increased BMI and obesity $[18,57]$. Beverage intake may contribute to a higher BMI by increasing TEI. This hypothesis is supported by several studies in children and adolescents [58, 59]. Greater effect estimates and significance in sugar-sweetened beverages in comparison to juices were observed in the current study. Both the higher levels of sugar in sugar-sweetened beverages and lower consumptions of juices could have contributed to this difference.

\section{Strengths and Limitations}

The current study has several strengths. Our analyses are based on two large population-based cohorts with measured anthropometric data. The food groups are defined according to the WHO food category system, which allows our results to be compared to future studies. Instead of providing isocaloric interpretations, the multivariate energy partition models allowed us to interpret our results while taking both energy and nonenergy effects of foods into account. Sensitivity analyses were nevertheless conducted using different models (i.e. multivariate standard model and multivariate density model; results not shown), and similar results were obtained.

Our study has some limitations. First, only cross-sectional data were available for this exploratory analysis. Thus, cause and effect associations cannot be drawn. Second, data on body composition and fat mass were not available. These data would have provided more information on weight status rather than only using BMI. However, it has been shown that the percentage of body fat and BMI have similar patterns over time [60]. Third, reporting bias may exist in our study as we used data collected from questionnaires. Differential, selective underreporting may have thus influenced our results, especially for overweight participants, as has been previously observed $[16,50,51]$. We did observe a higher proportion of underreporters in overweight participants for both males and females, although the definition of underreporters used in our study is not ideal. However, additional adjustment for the 'underreporter vs. plausible energy intake reporter' did not notably change our results. Still, the high proportion of potential underreporters (approx. 30\%) calls for the use of caution in future studies. 


\section{Conclusion}

Our results suggest that a high intake of meat, fish, beverages and bakery products is associated with increased body weight status. Particularly, meat intake may be an important correlate of being overweight. The influence of possible reverse causation on the association between food intake and being overweight needs to be explored in future studies.

\section{Acknowledgements}

GINIplus study group: Helmholtz Zentrum München, German Research Center for Environmental Health, Institute of Epidemiology I, Munich (J. Heinrich, H.E. Wichmann, S. Sausenthaler, A. Zutavern, C.M. Chen, M. Schnappinger and P. Rzehak); Department of Pediatrics, Marien Hospital, Wesel (D. Berdel, A. von Berg, C. Beckmann and I. Gross); Department of Pediatrics, Ludwig Maximilians University, Munich (S. Koletzko, D. Reinhardt and S. Krauss-Etschmann); Department of Pediatrics, Technical University, Munich (C.P. Bauer, I. Brochow, A. Grübl and U. Hoffmann), and IUF - Institut für Umweltmedizinische Forschung at Heinrich Heine University, Düsseldorf (U. Krämer, E. Link and C. Cramer).

LISAplus study group: Helmholtz Zentrum München, German Research Center for Environmental Health, Institute of Epidemiology I, Munich (J. Heinrich, H.E. Wichmann, S. Sausenthaler, C.M. Chen and M. Schnappinger); Department of Pediatrics, Municipal Hospital 'St. Georg', Leipzig (M. Borte and U. Diez); Department of Pediatrics, Marien Hospital Wesel, Wesel (A. von Berg, C. Beckmann and I. Gross); Pediatric Practice, Bad Honnef (B. Schaaf); Helmholtz Centre for Environmental Research - UFZ, Department of Environmental Immunology/Core Facility Studies, Leipzig (I. Lehmann, M. Bauer, C. Gräbsch, S. Röder and M. Schilde); University of Leipzig, Institute of Hygiene and Environmental Medicine, Leipzig (O. Herbarth, C. Dick and J. Magnus); IUF -
Institut für Umweltmedizinische Forschung, Düsseldorf (U. Krämer, E. Link and C. Cramer); Department of Pediatrics, Technical University Munich (C.P. Bauer and U. Hoffmann), and ZAUM - Center for Allergy and Environment, Technical University Munich (H. Behrendt, J. Grosch and F. Martin).

The GINIplus study was mainly supported for the first 3 years by the Federal Ministry for Education, Science, Research and Technology (interventional arm) and Helmholtz Zentrum Munich (former GSF; observational arm). The 4-, 6- and 10-year follow-up examinations of the GINIplus study were covered from the respective budgets of the 5 study centers [Helmholtz Zentrum Munich (former GSF), Research Institute at Marien Hospital Wesel, LMU Munich, Technical University Munich and from 6 years onwards also from IUF - Leibniz Research Institute for Environmental Medicine at Heinrich Heine University, Düsseldorf] and a grant from the Federal Ministry for Environment (IUF Düsseldorf, FKZ 20462296). The LISAplus study was mainly supported by grants from the Federal Ministry for Education, Science, Research and Technology and in addition from Helmholtz Zentrum Munich (former GSF), Helmholtz Centre for Environmental Research - UFZ, Leipzig, and Research Institute at Marien Hospital Wesel, Pediatric Practice, Bad Honnef for the first 2 years. The 4-, 6- and 10-year follow-up examinations of the LISAplus study were covered from the respective budgets of the involved partners [Helmholtz Zentrum Munich (former GSF), Helmholtz Centre for Environmental Research - UFZ, Leipzig, Research Institute at Marien-Hospital Wesel, Pediatric Practice, Bad Honnef, IUF Leibniz Research Institute for Environmental Medicine at Heinrich Heine University, Düsseldorf] and in addition by a grant from the Federal Ministry for Environment (IUF Düsseldorf, FKZ 20462296).

This work was supported by the Kompetenznetz Adipositas (Competence Network Obesity) funded by the Federal Ministry of Education and Research (FKZ: 01GI1121A).

\section{Disclosure Statement}

None to declare.

\section{References}

1 Chiolero A, Lasserre AM, Paccaud F, Bovet P: Childhood obesity: definition, consequences, and prevalence. Rev Med Suisse 2007;3:12621269.

2 James PT, Leach R, Kalamara E, Shayeghi M: The worldwide obesity epidemic. Obes Res 2001;9(suppl 4):228S-233S.

3 Mitchell NS, Catenacci VA, Wyatt HR, Hill JO: Obesity: overview of an epidemic. Psychiatr Clin North Am 2011;34:717-732.

4 Lloyd LJ, Langley-Evans SC, McMullen S: Childhood obesity and risk of the adult metabolic syndrome: a systematic review. Int J Obes (Lond) 2012;36:1-11.

5 Biro FM, Wien M: Childhood obesity and adult morbidities. Am J Clin Nutr 2010;91: 1499S-1505S.
-6 Breitfelder A, Wenig CM, Wolfenstetter SB, Rzehak P, Menn P, John J, Leidl R, Bauer CP, Koletzko S, Roder S, Herbarth O, von Berg A, Berdel D, Kramer U, Schaaf B, Wichmann HE, Heinrich J: Relative weight-related costs of healthcare use by children - results from the two German birth cohorts, GINI-plus and LISA-plus. Econ Hum Biol 2011;9:302315.

7 Hill JO, Wyatt HR, Peters JC: Energy balance and obesity. Circulation 2012;126:126-132.

8 Vitariusova E, Babinska K, Kost'alova L, Rosinsky J, Hlavata A, Pribilincova Z, Babinska K Jr, Kovacs L: Food intake, leisure time activities and the prevalence of obesity in schoolchildren in Slovakia. Cent Eur J Public Health 2010;18:192-197.
9 Bradlee ML, Singer MR, Qureshi MM, Moore LL: Food group intake and central obesity among children and adolescents in the Third National Health and Nutrition Examination Survey (NHANES III). Public Health Nutr 2010;13:797-805.

10 Rosenheck R: Fast food consumption and increased caloric intake: a systematic review of a trajectory towards weight gain and obesity risk. Obes Rev 2008;9:535-547.

11 Kral TV, Stunkard AJ, Berkowitz RI, Stallings VA, Brown DD, Faith MS: Daily food intake in relation to dietary energy density in the free-living environment: a prospective analysis of children born at different risk of obesity. Am J Clin Nutr 2007;86: 41-47. 
12 Lanfer A, Hebestreit A, Ahrens W: Diet and eating habits in relation to the development of obesity in children and adolescents (in German). Bundesgesundheitsblatt Gesundheitsforschung Gesundheitsschutz 2010;53:690-698.

-13 Summerbell CD, Douthwaite W, Whittaker V, Ells LJ, Hillier F, Smith S, Kelly S, Edmunds LD, Macdonald I: The association between diet and physical activity and subsequent excess weight gain and obesity assessed at 5 years of age or older: a systematic review of the epidemiological evidence. Int $\mathrm{J}$ Obes (Lond) 2009;33(suppl 3):S1-S92.

$\checkmark 14$ Willett WC, Howe GR, Kushi LH: Adjustment for total energy intake in epidemiologic studies. Am J Clin Nutr 1997;65:1220S$1228 \mathrm{~S}$, discussion 1229S-1231S.

15 Hu FB, Stampfer MJ, Rimm E, Ascherio A, Rosner BA, Spiegelman D, Willett WC: Dietary fat and coronary heart disease: a comparison of approaches for adjusting for total energy intake and modeling repeated dietary measurements. Am J Epidemiol 1999; 149: 531-540.

$\checkmark 16$ Collins CE, Watson J, Burrows T: Measuring dietary intake in children and adolescents in the context of overweight and obesity. Int J Obes (Lond) 2010;34:1103-1115.

-17 Cribb VL, Jones LR, Rogers IS, Ness AR, Emmett PM: Is maternal education level associated with diet in 10-year-old children? Public Health Nutr 2011;14:2037-2048.

-18 Hauner H, Bechthold A, Boeing H, Bronstrup A, Buyken A, Leschik-Bonnet E, Linseisen J, Schulze M, Strohm D, Wolfram G: Evidencebased guideline of the German Nutrition Society: carbohydrate intake and prevention of nutrition-related diseases. Ann Nutr Metab 2012;60(suppl 1):1-58.

$\checkmark 19$ von Berg A, Filipiak-Pittroff B, Kramer U, Hoffmann B, Link E, Beckmann C, Hoffmann U, Reinhardt D, Grubl A, Heinrich J, Wichmann HE, Bauer CP, Koletzko S, Berdel D: Allergies in high-risk schoolchildren after early intervention with cow's milk protein hydrolysates: 10-year results from the German Infant Nutritional Intervention (GINI) study. J Allergy Clin Immunol 2013;131:1565-1573.

20 von Berg A, Koletzko S, Filipiak-Pittroff B, Laubereau B, Grubl A, Wichmann HE, Bauer $\mathrm{CP}$, Reinhardt D, Berdel D: Certain hydrolyzed formulas reduce the incidence of atopic dermatitis but not that of asthma: three-year results of the German Infant Nutritional Intervention Study. J Allergy Clin Immunol 2007;119:718-725.

-21 Rzehak P, Sausenthaler S, Koletzko S, Reinhardt D, von Berg A, Kramer U, Berdel D, Bollrath C, Grubl A, Bauer CP, Wichmann HE, Heinrich J: Long-term effects of hydrolyzed protein infant formulas on growth - extended follow-up to $10 \mathrm{y}$ of age: results from the German Infant Nutritional Intervention (GINI) study. Am J Clin Nutr 2011;94:1803S$1807 \mathrm{~S}$.

22 Heinrich J, Bolte G, Holscher B, Douwes J, Lehmann I, Fahlbusch B, Bischof W, Weiss
M, Borte M, Wichmann HE: Allergens and endotoxin on mothers' mattresses and total immunoglobulin $\mathrm{E}$ in cord blood of neonates. Eur Respir J 2002;20:617-623.

23 World Health Organization. BMI-for-age cutoffs.http://www.who.int/growthref/who2007_ bmi_for_age/en/index.html; http://www.who. int/childgrowth/standards/bmi_for_age/en/ index.html.

24 World Health Organization. Growth reference 5-19 years. http://www.who.int/growthref/ who2007_bmi_for_age/en/index.html.

25 Stiegler P, Sausenthaler S, Buyken AE, Rzehak P, Czech D, Linseisen J, Kroke A, Gedrich K, Robertson C, Heinrich J: A new FFQ designed to measure the intake of fatty acids and antioxidants in children. Public Health Nutr 2010;13:38-46.

26 Food and Agriculture Organization of the United Nations/World Health Organization: Codex General Standard for Food Additives food category system. http://www.codex alimentarius.net/gsfaonline/docs/CXS_192e. pdf (accessed October 10, 2012).

27 Sichieri R, Yokoo EM, Pereira RA, Veiga GV: Water and sugar-sweetened beverage consumption and changes in BMI among Brazilian fourth graders after 1-year followup. Public Health Nutr 2013;16:73-77.

28 Mitchell JA, Pate RR, Beets MW, Nader PR: Time spent in sedentary behavior and changes in childhood BMI: a longitudinal study from ages 9 to 15 years. Int J Obes (Lond) 2012;37:54-60.

29 Mifflin MD, St Jeor ST, Hill LA, Scott BJ, Daugherty SA, Koh YO: A new predictive equation for resting energy expenditure in healthy individuals. Am J Clin Nutr 1990;51: 241-247.

30 Bandini LG, Schoeller DA, Dietz WH: Energy expenditure in obese and nonobese adolescents. Pediatr Res 1990;27:198-203.

31 Adriaens MP, Schoffelen PF, Westerterp KR: Intra-individual variation of basal metabolic rate and the influence of daily habitual physical activity before testing. Br J Nutr 2003;90: 419-423.

32 R Development Core Team. R: A Language and Environment for Statistical Computing. Vienna, Austria, 2010. http://www.R-project. org.

33 Global Database on Child Growth and Malnutrition. http://www.who.int/nutgrowthdb/ about/introduction/en/index5.html.

- 34 Kleiser C, Schaffrath Rosario A, Mensink GB, Prinz-Langenohl R, Kurth BM: Potential determinants of obesity among children and adolescents in Germany: results from the crosssectional KiGGS Study. BMC Public Health 2009;9:46.

-35 Assmann KE, Joslowski G, Buyken AE, Cheng G, Remer T, Kroke A, Gunther AL: Prospective association of protein intake during puberty with body composition in young adulthood. Obesity (Silver Spring) 2013;21:E782-E789.

36 Neumann CG, Jiang L, Weiss RE, Grillenberger M, Gewa CA, Siekmann JH, Murphy
SP, Bwibo NO: Meat supplementation increases arm muscle area in Kenyan schoolchildren. Br J Nutr 2013;109:1230-1240.

- 37 Albala C, Ebbeling CB, Cifuentes M, Lera L, Bustos N, Ludwig DS: Effects of replacing the habitual consumption of sugar-sweetened beverages with milk in Chilean children. Am J Clin Nutr 2008;88:605-611.

38 Bray GA, Smith SR, de Jonge L, Xie H, Rood J, Martin CK, Most M, Brock C, Mancuso S, Redman LM: Effect of dietary protein content on weight gain, energy expenditure, and body composition during overeating: a randomized controlled trial. JAMA 2012;307:47-55.

39 Freedman DS, Wang J, Maynard LM, Thornton JC, Mei Z, Pierson RN, Dietz WH, Horlick M: Relation of BMI to fat and fat-free mass among children and adolescents. Int J Obes (Lond) 2005;29:1-8.

40 Escribano J, Luque V, Ferre N, Mendez-Riera G, Koletzko B, Grote V, Demmelmair H, Bluck L, Wright A, Closa-Monasterolo R; European Childhood Obesity Trial Study Group: Effect of protein intake and weight gain velocity on body fat mass at 6 months of age: the EU Childhood Obesity Programme. Int J Obes 2012;36:548-553.

41 Gunther AL, Buyken AE, Kroke A: Protein in take during the period of complementary feeding and early childhood and the association with body mass index and percentage body fat at $7 \mathrm{y}$ of age. Am J Clin Nutr 2007;85: 1626-1633.

42 Günther AL, Buyken AE, Kroke A: The influence of habitual protein intake in early childhood on BMI and age at adiposity rebound: results from the DONALD Study. Int J Obes (Lond) 2006;30:1072-1079.

43 Karaolis-Danckert N, Gunther AL, Kroke A, Hornberg C, Buyken AE: How early dietary factors modify the effect of rapid weight gain in infancy on subsequent body-composition development in term children whose birth weight was appropriate for gestational age. Am J Clin Nutr 2007;86:1700-1708.

44 Hoek AC, Luning PA, Stafleu A, de Graaf C: Food-related lifestyle and health attitudes of Dutch vegetarians, non-vegetarian consumers of meat substitutes, and meat consumers. Appetite 2004;42:265-272.

45 Davey GK, Spencer EA, Appleby PN, Allen NE, Knox KH, Key TJ: EPIC-Oxford: lifestyle characteristics and nutrient intakes in a cohort of 33883 meat-eaters and 31546 non meat-eaters in the UK. Public Health Nutr 2003;6:259-269.

46 Kipping RR, Jago R, Lawlor DA: Obesity in children. Part 1: epidemiology, measurement, risk factors, and screening. BMJ 2008;337: a1824.

47 Malik VS, Willett WC, Hu FB: Global obesity: trends, risk factors and policy implications. Nat Rev Endocrinol 2013;9:13-27.

48 Parnell W, Wilson N, Alexander D, Wohlers M, Williden M, Mann J, Gray A: Exploring the relationship between sugars and obesity. Public Health Nutr 2008;11:860-866. 
49 Gibson S, Neate D: Sugar intake, soft drink consumption and body weight among British children: further analysis of National Diet and Nutrition Survey data with adjustment for under-reporting and physical activity. Int J Food Sci Nutr 2007;58:445-460.

-50 Ambrosini GL, Emmett P, Northstone K, Howe LD, Tilling K, Jebb SA: Identification of a dietary pattern prospectively associated with increased adiposity during childhood and adolescence. Int J Obesity 2012;36:12991305.

-51 Fisher JO, Johnson RK, Lindquist C, Birch LL, Goran MI: Influence of body composition on the accuracy of reported energy intake in children. Obes Res 2000;8:597-603.

52 Anderson GH, Woodend D: Consumption of sugars and the regulation of short-term satiety and food intake. Am J Clin Nutr 2003;78: 843S-849S.
53 O’Neil CE, Fulgoni VL 3rd, Nicklas TA: Association of candy consumption with body weight measures, other health risk factors for cardiovascular disease, and diet quality in US children and adolescents: NHANES 19992004. Food Nutr Res 2011;55, DOI: 10.3402/ fnr.v55i0.5794.

54 Amin TT, Al-Sultan AI, Ali A: Overweight and obesity and their association with dietary habits, and sociodemographic characteristics among male primary school children in Al-Hassa, Kingdom of Saudi Arabia. Indian J Community Med 2008;33:172-181.

55 Atkinson FS, Foster-Powell K, Brand-Miller JC: International tables of glycemic index and glycemic load values: 2008. Diabetes Care 2008;31:2281-2283.

56 Gogebakan O, Kohl A, Osterhoff MA, van Baak MA, Jebb SA, Papadaki A, Martinez JA, Handjieva-Darlenska T, Hlavaty P, Weickert MO, Holst C, Saris WH, Astrup A, Pfeiffer AF: Effects of weight loss and long-term weight maintenance with diets varying in protein and glycemic index on cardiovascular risk factors: the diet, obesity, and genes (DiOGenes) study: a randomized, controlled trial. Circulation 2011;124:2829-2838.
57 Libuda L, Alexy U, Sichert-Hellert W, Stehle P, Karaolis-Danckert N, Buyken AE, Kersting M: Pattern of beverage consumption and longterm association with body-weight status in German adolescents - results from the DONALD study. Br J Nutr 2008;99:1370-1379.

-58 O'Connor TM, Yang SJ, Nicklas TA: Beverage intake among preschool children and its effect on weight status. Pediatrics 2006;118:e1010e1018.

59 Rodriguez-Artalejo F, Garcia EL, Gorgojo L, Garces C, Royo MA, Martin Moreno JM, Benavente $\mathrm{M}$, Macias A, De Oya M: Consumption of bakery products, sweetened soft drinks and yogurt among children aged 6-7 years: association with nutrient intake and overall diet quality. Br J Nutr 2003;89:419-429.

60 Plachta-Danielzik S, Gehrke MI, Kehden B, Kromeyer-Hauschild K, Grillenberger $M$, Willhöft C, Bosy-Westphal A, Müller MJ: Body fat percentiles for German children and adolescents. Obes Facts 2012;5:77-90. 